\title{
Low expression of long noncoding RNA CDKN2B-AS1 in patients with idiopathic pulmonary fibrosis predicts lung cancer by regulating the p53-signaling pathway
}

\author{
YUFENG DU, XIAOYAN HAO and XUEJUN LIU \\ Department of Geriatric Diseases, The First Affiliated Hospital of Shanxi Medical University, Taiyuan, \\ Shanxi 030001, P.R. China
}

Received August 30, 2016; Accepted September 15, 2017

DOI: $10.3892 / \mathrm{ol} .2018 .7910$

\begin{abstract}
The present study aimed to investigate the expression of long non-coding RNA (lncRNA) cyclin dependent kinase inhibitor-2B-antisense RNA 1 CDKN2B-AS1 in patients with peripheral blood of idiopathic pulmonary fibrosis (IPF). A total of 24 patients with IPF and 24 healthy controls were included in the study, four patients with IPF and four healthy controls were selected randomly to extract RNA. There were no other diseases such as hypertension and diabetes in the two groups. RNA from peripheral blood was extracted by high-throughput sequencing and bioinformatics analysis was performed. Based on selected differentially expressed lncRNA and mRNA, gene ontology analysis was performed to screen out the tumor-associated mRNA. A total of 20 samples were chosen to avoid variance due to individual differences. A total of 20 patients with IPF, and 20 controls were further studied, RNA extracted from peripheral blood was used to verify the lncRNA and mRNA levels. A total of 440 lncRNAs were identified to be upregulated and 1,376 downregulated according to the screening results of differential expression. High-throughput sequencing and bioinformatics analysis demonstrated that the expression of CDKN2B-AS1 decreased significantly in patients with IPF compared with healthy controls. The adjacent gene mRNA of CDKN2B-AS1 was identified as CDKN2A, an important anti-oncogene, which is concentrated on the p53 signaling-pathway according to the Kyoto Encyclopedia of Genes and Genomes database. CDKN2A mRNA expression levels were lower in patients with IPF and higher in the control group. The expression of CDKN2B-AS1 and CDKN2A mRNA was significantly lower in IPF group compared with in the control group $(\mathrm{P}<0.05)$.
\end{abstract}

Correspondence to: Dr Xuejun Liu, Department of Geriatric Diseases, The First Affiliated Hospital of Shanxi Medical University, 85 Jiefang South Road, Taiyuan, Shanxi 030001, P.R. China

E-mail:1xj20041205@sina.com

Key words: long non-coding RNA, idiopathic pulmonary fibrosis, lung cancer, p53-signaling pathway, adjacent genes
The results suggest the expression of the CDKN2B-AS1 and adjacent gene, CDKN2A, are downregulated in the peripheral blood of patients with IPF, which activates the p53-signaling pathway to promote lung cancer formation.

\section{Introduction}

Idiopathic pulmonary fibrosis (IPF) is a progressive and usually fatal lung disease characterized by fibroblast proliferation, and extracellular matrix remodeling $(1,2)$. It is a common disease in the elderly population, particularly those who are between 50-70 years old. IPF may be associated with additional comorbidities, which have an impact on the quality of life and survival of patients in addition to the progressive exertional dyspnea. IPF has a small number of treatment options. Therefore, it is hypothesized that since there are no effective therapies, timely detection and reduction of the complications are important in order to improve the quality of life of patients. It has been reported that IPF is an independent risk factor of lung cancer $(1,2)$, with non-small cell lung carcinoma (NSCLC) being the main pathological type. However, the underlying mechanism remains poorly understood.

Epigenetic alterations are involved in the pathogenesis of IPF and lung cancer. Long non-coding RNA (lncRNA) is a class of RNA with the length of $>200$ bases. With the development of gene sequencing technology and bioinformatics technology, increasing evidence has demonstrated that changes in lncRNA expression levels are associated with numerous diseases including lung disease and neurological disease $(3,4)$. The p53 gene has been revealed to have the highest number of genetic correlations with human tumor types and is an important tumor suppressor gene (5). The p53-mediated cell-signaling pathway serves an important role in the regulation of normal cellular activities.

Studies have demonstrated that lncRNA alterations and the p53-signaling pathway are involved in the process of IPF, and lung cancer formation. Therefore, it was hypothesized that there are certain changes in lncRNA related to the p53 gene, further associating IPF with lung cancer. Thus, the present study aimed to investigate the differential expression of lncRNAs through high-throughput sequencing and bioinformatics analysis. 


\section{Materials and methods}

Study population. A total of 24 patients with IPF, according to diagnostic criteria established by the American Thoracic Society (6), and 24 healthy controls were involved in the study (all males; aged $67 \pm 3.2$ vs. $64 \pm 2.8$ years, respectively; $\mathrm{P}>0.05)$. Based on the uniformity of background including age and gender, four patients with IPF and four healthy controls were selected for RNA extraction. RNA from peripheral blood was extracted using high-throughput sequencing and bioinformatics analysis was performed for the expression of lncRNA. The remaining 20 patients with IPF and 20 healthy controls were further studied; RNA extracted from peripheral blood was used to verify the lncRNA and mRNA. The $3 \mathrm{ml}$ of blood sample was stored in $-70^{\circ} \mathrm{C}$ for further study. The present study was approved by the Shanxi Medical University Ethics Committee (Taiyuan, China). Written informed consent was obtained from each patient and healthy individuals.

RNA extraction. Total RNA was isolated using TRIzol (Invitrogen; Thermo Fisher Scientific, Inc.) according to the manufacturer's protocol. RNA concentration and quality were assessed using a NanoDrop ND-1000 Spectrophotometer (NanoDrop Technologies; Thermo Fisher Scientific, Inc., Waltham, MA, USA). The ratio A260/A280 was between 1.8-2.1.

RNA sequencing. Ribosomal (r)RNA was removed the total RNA $(1 \mu \mathrm{g})$ samples using the Ribo-Zero Gold kit (Illumina, Inc., San Diego, CA, USA) according to the manufacturer's protocol. The rRNA-depleted samples were used for library construction using the NEBNext ${ }^{\circledR}$ Ultra $^{\mathrm{TM}}$ RNA Library Prep kit according to the manufacturer's protocol (New England Biolabs, Inc., Ipswich, MA, USA). Libraries were sequenced with the Illumina HiSeq Sequencer according to the manufacturer's protocol (Illumina, San Diego, CA, USA). Reads were trimmed and cleaned of Illumina adaptors, and low quality sequences using Cutadapt software (version 1.9.2; https://github.com/marcelm/cutadapt). Clean reads were mapped to the Human genome [University of California Santa Cruz(UCSC)hg19; http://genome.ucsc.edu/cgi-bin/hgGateway] using TopHat2 software (version 2.1.2; http://ccb.jhu .edu/software/tophat/index.shtml) and unmapped reads were discarded. Cuffdiff software (version 2.1.2; part of cufflinks; https://github.com/cole-trapnell-lab/cufflinks) was used to perform expression analysis and differential expression analysis. LncRNAs were considered to be differentially expressed based on Fragments/kb of transcript/million mapped reads $($ FPKM $)>0.5$ and fold change $>2.0$.

Gene ontology (GO) analysis and pathway analysis. The GO enrichment analysis was performed for functional analysis of LncRNA-associated genes using R package 'topGO' from Bioconductor (http://www.bioconductor .org/packages/release/bioc/html/topGO.html). The significant pathways for predicting target genes were identified according to the Kyoto Encyclopedia of Genes and Genomes (KEGG) database (http://www.genome.jp/kegg/). The Fisher's exact test was used to select the significant Gene ontology and pathways, and the threshold of significance was defined by $\mathrm{P}<0.05$. RNA
Sequencing reads may be mapped into the reference genome. Any gene of interest may be directly visualized in the Integrative Genomics Viewer (http://www.broadinstitute.org/igv/).

cDNA synthesis and reverse transcription-quantitative polymerase chain reaction $(R T-q P C R)$. Total RNA was used to make cDNA using PowerScript RT-PCR kit (Cloud-Seq Inc., Shanghai, China) according to the manufacturer's protocol with random primers supplied with the kit. The expression levels of IncRNAs and mRNAs were determined using SYBR Green I-based qPCR. The qPCR thermocycling conditions were maintained as follows: $95^{\circ} \mathrm{C}$ for $10 \mathrm{~min}$; followed by 40 cycles of $95^{\circ} \mathrm{C}$ for $10 \mathrm{sec}$ and $60^{\circ} \mathrm{C}$ for $60 \mathrm{sec}$. Data were analyzed using the comparative $\Delta \mathrm{Cq}$ method (7) with $\beta$-actin as an endogenous reference gene. Primers were designed using Primer (version 5.0; https://wheat.pw.usda.gov/demos/BatchPrimer3/). The primers used were as follows: Cyclin dependent kinase inhibitor (CDKN)2B-antisense RNA 1 (AS1) forward, AACCGG GGAGATCTATTTGG and reverse, GGTGTGGTGTCTCAC ACCTG; CDKN2A forward, GGCTGTTCCTGGTCATGAT and reverse, TGTCCAGGAAGCCCTCC.

Statistical analysis. Results are expressed as the mean \pm standard deviation. Differences between groups were analyzed by one-way analysis of variance (ANOVA). Bonferroni post hoc test was used to identify which comparison is significantly different after ANOVA analysis. Statistical significance was determined using SPSS software (version 17.0; SPSS, Inc., Chicago, IL, USA). P<0.05 was considered to indicate a statistically significant difference.

\section{Results}

lncRNA expression. A total of 1,816 differentially expressed lncRNAs were identified via screening, including 440 upregulated and 1,376 downregulated lncRNAs (Fig. 1). In addition, 1,124 differentially expressed mRNAs were identified (Fig. 2). Notably, downregulated lncRNAs were more common compared with upregulated lncRNAs. Among the lncRNAs, CDKN2B-AS1 (chr9:21802541-22121096) was identified to be the most significantly downregulated lncRNA.

Pathway analysis. The significant pathways for predicting the target gene were identified according to the KEGG database using Fisher's exact test. The p53-signaling pathway was significantly associated with lung cancer (Fisher's exact test; $\mathrm{P}<0.013$ ) and target gene-related pathways (Fisher's exact test; $\mathrm{P}<0.0039$; Fig. 3; Table I).

Target lncRNA. CDKN2A is an important component of the p53-signaling pathway. Using bioinformatics analysis, it was revealed that the adjacent mRNA gene of CDKN2A was CDKN2B-AS1. Through the aforementioned selected differentially expressed lncRNA and mRNA, the key lncRNA is CDKN2B-AS1 (chr9:21802541-22121096) with change of 3.78-folds. Differentially expressed lncRNA and mRNA were screened out and it was found that CDKN2B-AS1 (chr9:21802541-22121096) decreased significantly in IPF patients. The gene ID of CDKN2B-AS1 is ENSG00000240498. 


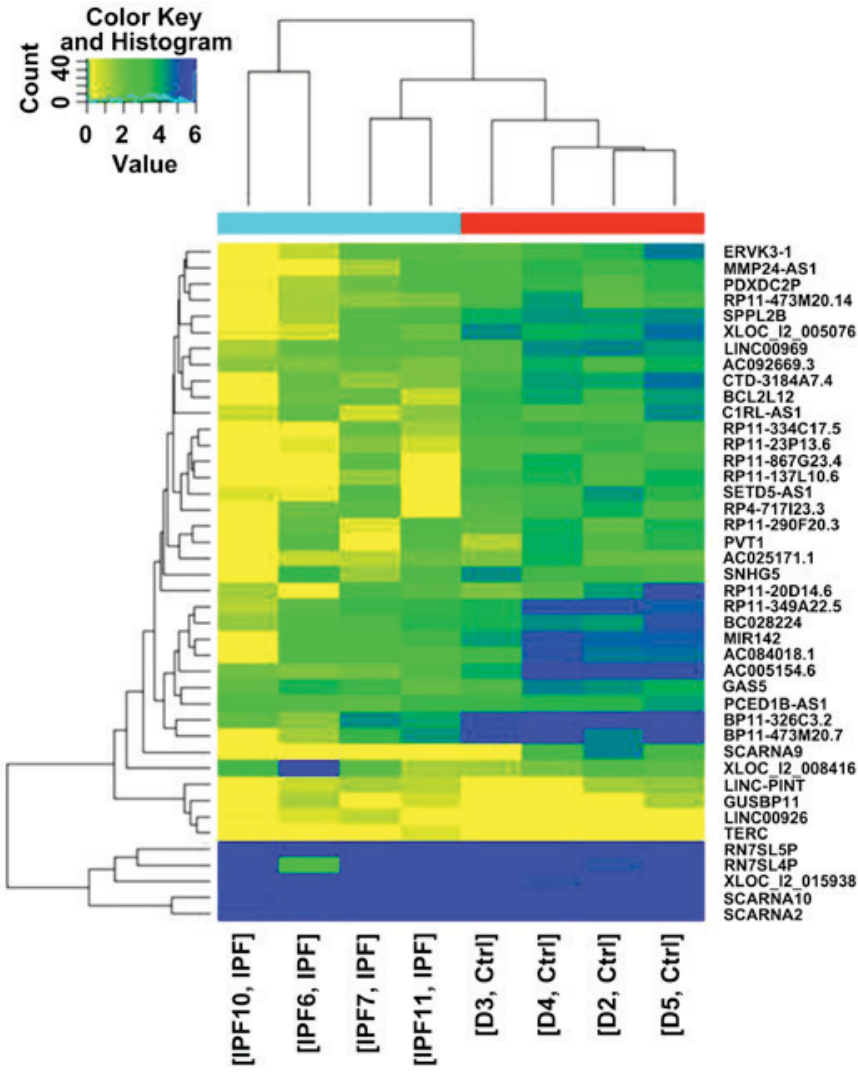

Figure 1. Differentially expressed lncRNA. An lncRNA expression signature of IPF. 1816 differentially expressed lncRNAs (rows) from hierarchical clustering were identified between IPF samples and normal samples (columns). Patient ID numbers are shown below the columns. The expression level of each IncRNA is represented by the number of standard deviations above (blue) or below (green) the average value for that gene across all samples. IncRNA, long noncoding RNA.

According to the UCSC database, the CDKN2B-AS1 gene length is $631 \mathrm{bp}$. CDKN2B-AS1 was identified in the 'Homo_sapiens_HG19.sorted.gtf' database.

From the Ensembl database (http://www.ensembl .org/Homo_sapiens/Info/Index) and CNKI gene database, the transcript of CDKN2A was demonstrated to contain an alternate open reading frame (ARF) that encodes a protein, which is structurally unassociated with the products of the other variants. This ARF product functions as a stabilizer of the tumor suppressor protein p53 as they can interact with each other (8). This gene is known as an important tumor suppressor gene and is associated with IPF. The positional association between the two genes is antisense (Fig. 4), and the adjacent gene of the CDKN2B-AS1 is CDKN2A. It further suggests that these two genes CDKN2B-AS1 and CDKN2A are simultaneously transcribed. This lncRNA is located on chromosome 9 at the approximate location chr9:21802541-22121096 and the adjacent gene is CDKN2A in Fig. 4.

From the aforementioned results, the CDKN2B-AS1 and CDKN2A expression levels were determined in the remaining IPF and control group cases ( $\mathrm{n}=20$ each) using RT-qPCR technology. The results revealed that CDKN2B-AS1 and CDKN2A expression levels were significantly decreased in the IPF group compared with the control group ( ${ }^{*} \mathrm{P}<0.05$; Fig. 5).

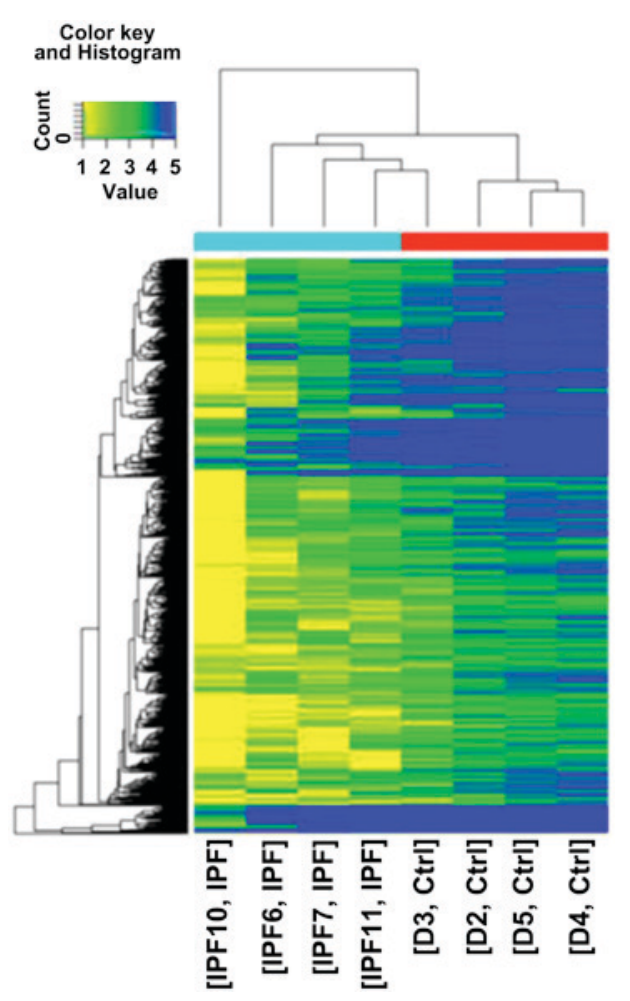

Figure 2. Differentially expressed mRNA. An mRNA expression signature of IPF. 1485 differentially expressed mRNAs (rows) from hierarchical clustering were identified between IPF samples and normal samples (columns). Patient ID numbers are shown below the columns. The expression level of each lncRNA is represented by the number of standard deviations above (blue) or below (green) the average value for that gene across all samples.

Top Significant Pathways of DE Genes

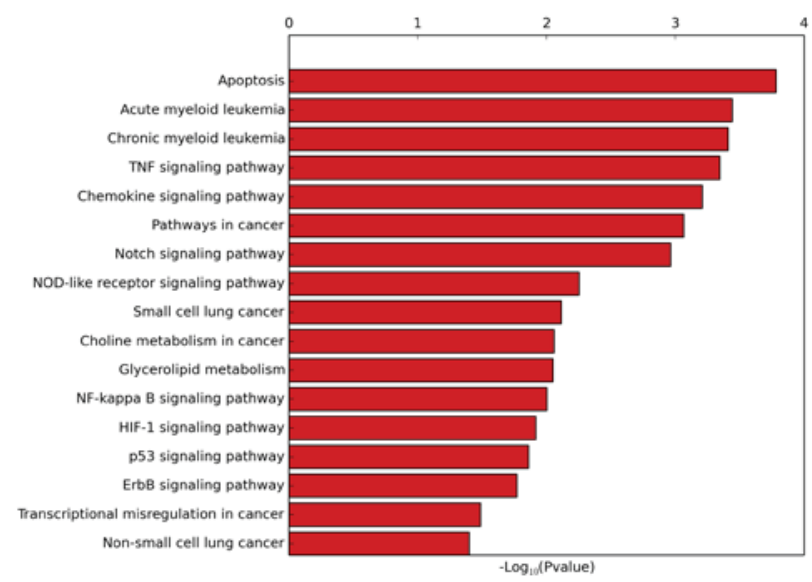

Figure 3. Target gene-related enriched pathways. p53-signaling pathway in the top significant pathway of different genes according to the pathway analysis, which is the one of the bioinformatics analysis. DE, differentially

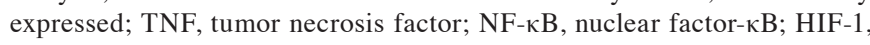
hypoxia inducible factor-1; ErbB, epidermal growth factor family of receptor tyrosine kinases.

\section{Discussion}

IPF is a chronic, progressive and fatal diffuse interstitial lung disease. It has re-emerged as a focus of scientific study, due to its increasing incidence, the progressive dyspnea and lack of effective treatments (9). The diagnosis of IPF often 
Table I. Target gene-associated pathways.

\begin{tabular}{|c|c|c|c|c|c|c|}
\hline Pathway ID & Definition & $\begin{array}{l}\text { Fisher } \\
\text { P-value }\end{array}$ & $\begin{array}{l}\text { Selection } \\
\text { counts }\end{array}$ & Size & $\begin{array}{l}\text { Enrichment- } \\
\text { score }\end{array}$ & Genes \\
\hline hsa04115 & p53-signaling pathway & 0.013 & 24 & 6890 & 1.86 & $\begin{array}{l}\text { APAF1//BAI1//BAX//BBC3// } \\
\text { CASP8//CASP9//CCND3//CCNG2// } \\
\text { CD82//CDK2//CDKN1A//CDKN2A// } \\
\text { CHEK1//CYCS//DDB2//IGFBP3// } \\
\text { RCHY1//RFWD2//RRM2B//SHISA5// } \\
\text { TNFRSF10B//TP53//TSC2//ZMAT3 }\end{array}$ \\
\hline hsa04330 & Notch-signaling pathway & 0.001 & 21 & 6890 & 2.96 & $\begin{array}{l}\text { APH1A//CREBBP//CTBP2//DTX1// } \\
\text { DTX3//DVL1//DVL2//DVL3//HDAC1// } \\
\text { HDAC2//JAG2//KAT2A//LFNG// } \\
\text { MFNG//NCOR2//NCSTN//NOTCH1// } \\
\text { NOTCH2//NUMB//PSENEN//RFNG }\end{array}$ \\
\hline hsa04621 & $\begin{array}{l}\text { NOD-like receptor-signaling } \\
\text { pathway }\end{array}$ & 0.005 & 22 & 6890 & 2.52 & $\begin{array}{l}\text { CARD6//CARD8//CARD9//CASP5// } \\
\text { CASP8//CHUK//CXCL1//IKBKB// } \\
\text { MAPK13//MAPK14//MAPK3//MEFV// } \\
\text { NFKB1//NLRP1//NLRP3//NOD1// } \\
\text { NOD2//PSTPIP1//PYCARD//RELA// } \\
\text { SUGT1//TNF }\end{array}$ \\
\hline hsa04668 & TNF signaling pathway & $<0.001$ & 41 & 6890 & 3.34 & $\begin{array}{l}\text { AKT1//AKT2//BCL3//CASP10// } \\
\text { CASP8//CEBPB//CHUK//CREB1// } \\
\text { CREB3L2//CSF1//CXCL1//CXCL5// } \\
\text { FADD//FOS//ICAM1//IKBKB//IL15// } \\
\text { JUNB//MAP2K6//MAP2K7//MAP3K5// } \\
\text { MAPK13//MAPK14// MAPK3// } \\
\text { MMP14//MMP9//NFKB1// NOD2// } \\
\text { PGAM5//PIK3CD//PIK3R5//PTGS2// } \\
\text { RELA//RIPK1//RIPK3//RPS6KA5// } \\
\text { TNF//TNFRSF1B//TRADD// } \\
\text { TRAF1//TRAF3 }\end{array}$ \\
\hline hsa05222 & Small cell lung cancer & 0.008 & 30 & 6890 & 2.11 & $\begin{array}{l}\text { AKT1//AKT2//APAF1//BCL2//CASP9// } \\
\text { CDK2//CDKN1B//CDKN2B//CHUK// } \\
\text { COL4A3//CYCS//E2F2//FHIT// } \\
\text { IKBKB//ITGA3//ITGA6//ITGAV// } \\
\text { LAMA5//LAMB2//LAMC3//MYC// } \\
\text { NFKB1//PIK3CD//PIK3R5//PTGS2// } \\
\text { RELA//TP53//TRAF1//TRAF3//TRAF4 }\end{array}$ \\
\hline hsa05223 & Non-small cell lung cancer & 0.004 & 19 & 6890 & 1.399 & $\begin{array}{l}\text { AKT1//AKT2//ARAF//CASP9// } \\
\text { CDKN2A//E2F2//FHIT// } \\
\text { GRB2//HRAS//MAPK3//PDPK1// } \\
\text { PIK3CD//PIK3R5//PLCG1//PRKCA// } \\
\text { PRKCB//RASSF1//TGFA//TP53 }\end{array}$ \\
\hline
\end{tabular}

CDKN2A is in the p53-signaling pathway. The Fisher P-values were 0.013 and 0.0039 . CDKN2A was identified to be concentrated on the p53-signaling pathway according to the high-throughput sequencing results. TNF, tumor necrosis factor; CDKN2A, cyclin dependent kinase inhibitor 2A; NOD, nucleotide-binding oligomerization domain.

requires a multidisciplinary approach, involving pulmonologists, radiologists, and pathologists experienced in the field of interstitial lung diseases $(6,10)$. As early as 1957 , the incidence of lung cancer in patients with IPF was identified to be higher, compared with healthy control patients. (11), is has been confirmed that the incidence of lung cancer is increased in patients with IPF compared to the general population (12-16). A previous study identified that IPF is an independent risk factor of lung cancer (14). Recently, the view that lung cancer occurs as a late complication of IPF 


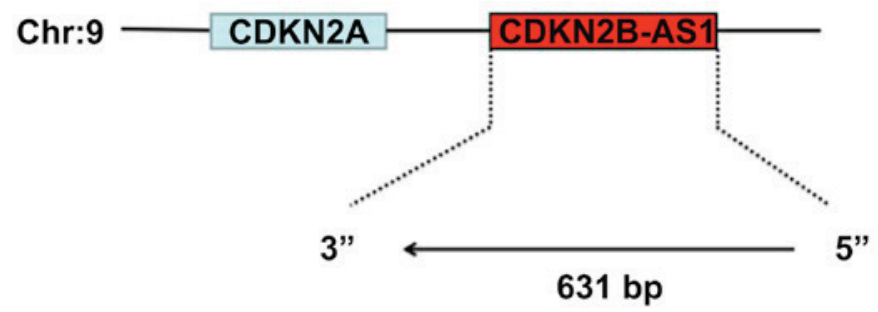

Figure 4. Association between CDKN2A and CDKN2B-AS1. This long noncoding RNA is located on chromosome 9 at approximate locations (chr9:21802541-22121096), and the adjacent gene is CDKN2A. CDKN2B-AS1, cyclin dependent kinase inhibitor 2B-antisense RNA 1; Chr, chromosome.

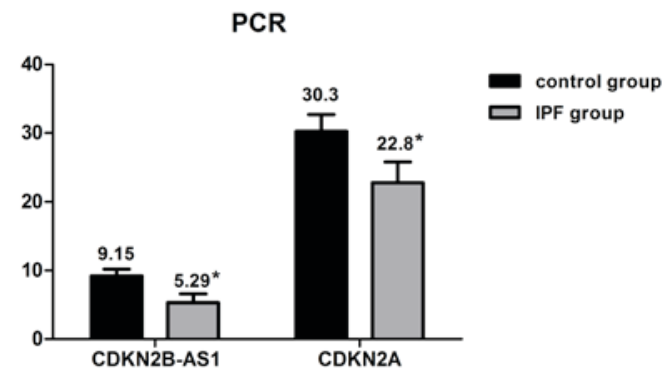

Figure 5. Validation of long noncoding RNA and mRNA microarray data by reverse transcription-quantitative PCR. The relative expression level of each IncRNA and mRNA were normalized. Data are presented as the mean \pm standard deviation, ${ }^{\mathrm{P}}<0.05$. PCR, polymerase chain reaction; IPF, idiopathic pulmonary fibrosis.

rather than being incidental has been supported (17). Studies consistently demonstrated that elderly male patients with IPF with a history of smoking are more likely to develop lung cancer (18-20).

Typical HRCT findings from lung cancer with IPF are well-defined nodules with lobulation in the peripheral subpleural areas inside or adjacent to the fibrosis (21). Kim et al (22) reported that the highest proportion of IPF with lung cancer cases is adenocarcinoma, but Lee et al (23) reported that the highest proportion was squamous cell carcinoma. These two differences may be associated with the different sample populations that were chosen; however, patients with IPF are prone to having non-small cell lung cancer (24). It has been reported that the incidence of IPF associated with lung cancer is inconsistent, which may be due to the different diagnostic criteria used. Certain reports have noted the incidence of lung cancer as $4.8-48 \%$ and without pulmonary fibrosis as $2.0-6.4 \%$ (1), thus it has been considered that IPF is a precancerous condition. IPF has been associated with lung cancer; however, the underlying mechanism remains to be elucidated. There are a number of genes and signaling pathways involved in this process, including the p53-signaling pathway.

Of all humans cancers, 50\% lack a wild-type p53 allele and thus fail to produce a normal version of the p53 protein (5). The presence of multiple mutations in the p53 gene may explain the high incidence of IPF complicated by lung carcinoma (25). Kawasaki et al (26) have reported that tumor suppressor p53 is altered in squamous metaplasia, and dysplastic bronchial and alveolar epithelia in patients with IPF. Exposure to carcinogens, tobacco and aging may cause the inactivation of tumor suppressor genes, and lead to lung cancer in patients with IPF (1). Reduced levels of p53 have been identified in cancer of the colon, lung, esophagus, breast, liver, brain, reticuloendothelial tissues and hemopoietic tissues. The incidence of positive anti-p53 antibody in IPF, irrespective of the existence of lung cancer, was as high as that in lung cancer (27). These findings suggest that the p53-signaling pathway is associated with lung cancer (28-30) and with IPF (31). Thus, we hypothesized that p53 mutation downregulation may be associated with a high incidence of lung cancer in patients with IPF.

Previously, IncRNA molecules were generally considered as byproducts formed during the transcription of the genome, and were defined as transcriptome 'background noise' without biological functions. It has now been reported that lncRNAs are involved in numerous important biological processes, including gene imprinting, cell proliferation and differentiation, immune responses, and chromosome structure. LncRNA may serve a role in a variety of mechanisms, including the following: Rupturing of small RNA (shortRNAs); specific binding to chromosomes in Hox gene loci; regulating epigenetic activity by transacting; RNA may also form DNA-DNA-RNA triple helix structures to inhibit promoter activity; coding mRNA antisense transcripts to regulate gene activity (32). Previously, research confirmed that lncRNA is associated with numerous chronic pulmonary disease types, which serves important roles in the biological processes of lung cancer and IPF (33).

Through microarray analysis of bleomycin-induced pulmonary fibrosis in a mouse model, the differential expression of lncRNA was confirmed (34). Furthermore, lncRNA imbalance is a characteristic of numerous types of cancer, which may be involved in promoting tumor progression, invasion and metastasis (35-37). lncRNA has been demonstrated to be involved in cell proliferation, apoptosis, epithelial-mesenchymal transition and other biological processes, which regulate tumorigenesis, and metastasis (38-40). IncRNAs may either facilitate or inhibit the progression of lung cancer and the various pathways involved (41-43).

In the present study, differentially expressed lncRNAs were screened in IPF, IncRNA CDKN2B-AS1 was screened and a fold-change of 3.78 FPKM was observed $(\mathrm{P}<0.05)$. The gene ID for CDKN2B-AS1 was ENSG00000240498. According to the UCSC database, the CDKN2B-AS1 gene length was $631 \mathrm{bp}$. However, there is currently little research on CDKN2B-AS1. Certain reports have noted that CDKN2B-AS1 is associated with hypertension and myocardial injury (44). In genome wide association studies of individual cancer types, genetic polymorphisms in the CDKN2A/2B-AS1/2B/methylthioadenosine phosphorylase gene cluster were associated with melanoma (45).

There are several mechanisms of IncRNA, it is able to inhibit the expression of certain genes and may enhance the expression of its neighboring gene $(46,47)$. A previous study demonstrated that lncRNAs serve an important role in the process of transcription, particularly that of neighboring genes (33). It has been reported that adjacent pairs of genes often exhibit correlated expression patterns throughout the cell cycle (48-50). IncRNAs may regulate the transcription of adjacent genes, thus affecting their biological roles. According to the bioinformatics analysis in the present study, it was 
revealed that the adjacent gene mRNA of CDKN2B-AS1 was CDKN2A. CDKN2A is the cyclin-dependent kinase inhibitor, which is an important tumor suppressor gene. It is involved in the regulation of cell proliferation and apoptosis, encoding proteins p16INK4a and p14ARF serve a function via retinoblastoma protein and $\mathrm{p} 53$ protein respectively (51). Altered expression levels of the CDKN2A gene have been reported in numerous tumor types such as tumors of lung, breast, brain, bone, skin, bladder, kidney, ovary, and lymphocyte (52), thus, there it is a focus of oncogenetic studies. CDKN2A is considered as an exogenous marker, which is able to be detected at an early stage of sputum and bronchoalveolar lavage fluid in patients with lung cancer (53). Busch et al (8) identified that induction of ARF is an early response in lung tumorigenesis that mounts a barrier against tumor growth and malignant progression. According to the GeneWays7.0 database, Li et al (54) reported that CDKN2A is associated with non-small lung cancer. In addition, Cisneros et al (55) demonstrated that many IPF fibroblasts exhibit decreased expression of the proapoptotic p14ARF attributable to promoter hypermethylation (55). The present study revealed that CDKN2A expression was decreased significantly in patients with IPF, which was consistent with previous report (55). Furthermore, CDKN2A expression was concentrated on the p53-signaling pathway according to the high-throughput sequencing results. It is involved in the regulation of gene $\mathrm{p} 53$, there may be a key factor in IPF patients with lung cancer.

In conclusion, the current study demonstrated that CDKN2B-AS1 expression is decreased significantly in patients with IPF, while its adjacent gene CDKN2A expression is reduced simultaneously. Thus, it may promote the occurrence of lung cancer by regulating p53-signaling pathways.

\section{References}

1. Ozawa Y, Suda T, Naito T, Enomoto N, Hashimoto D, Fujisawa T, Nakamura $\mathrm{Y}$, Inui $\mathrm{N}$, Nakamura $\mathrm{H}$ and Chida $\mathrm{K}$ : Cumulative incidence of and predictive factors for lung cancer in IPF. Respirology 14: 723-728, 2009.

2. Artinian V and Kvale PA: Cancer and interstitial lung disease. Curr Opin Pulm Med 10: 425-434, 2004.

3. Carninci P, Kasukawa T, Katayama S, Gough J, Frith MC Maeda N, Oyama R, Ravasi T, Lenhard B, Wells C, et al: The transcriptional landscape of the mammalian genome. Science 309: 1559-1563, 2005.

4. Mehler MF and Mattick JS: Noncoding RNAs and RNA editing in brain development, functional diversification, and neurological disease. Physiol Rev 87: 799-823, 2007.

5. Kaelin WG Jr: The emerging p53 gene family. J Natl Cancer Inst 91: 594-598, 1999.

6. American Thoracic Society. Idiopathic pulmonary fibrosis: Diagnosis and treatment. International consensus statement. American Thoracic Society (ATS) and the European Respiratory Society (ERS). Am J Respir Crit Care Med 161: 646-664, 2000.

7. Silver N, Best S, Jiang J and Thein SL: Selection of housekeeping genes for gene expression studies in human reticulocytes using real-time PCR. BMC Mol Biol 7: 33, 2006.

8. Busch SE, Moser RD, Gurley KE, Kelly-Spratt KS, Liggitt HD and Kemp CJ: ARF inhibits the growth and malignant progression of non-small-cell lung carcinoma. Oncogene 33: 2665-2673, 2014.

9. Collard HR and Pantilat SZ: Dyspnea in interstitial lung disease. Curr Opin Support Palliat Care 2: 100-104, 2008.

10. King TE Jr, Pardo A and Selman M: Idiopathic pulmonary fibrosis. Lancet 378: 1949-1961, 2011.
11. Spain DM: The association of terminal bronchiolar carcinoma with chronic interstitial inflammation and fibrosis of the lungs. Am Rev Tuberc 76: 559-566, 1957.

12. Song DH, Choi IH, Ha SY, Han KM, Lee JJ, Hong ME, Jeon K, Chung MP, Kim J and Han J: Usual interstitial pneumonia with lung cancer: Clinicopathological analysis of 43 cases. Korean J Pathol 48: 10-16, 2014.

13. Le Jeune I, Gribbin J, West J, Smith C, Cullinan P and Hubbard R: The incidence of cancer in patients with idiopathic pulmonary fibrosis and sarcoidosis in the UK. Respir Med 101: 2534-2540, 2007.

14. Matsushita H, Tanaka S, Saiki Y, Hara M, Nakata K, Tanimura S and Banba J: Lung cancer associated with usual interstitial pneumonia. Pathol Int 45: 925-932, 1995.

15. Turner-Warwick M, Lebowitz M, Burrows B and Johnson A: Cryptogenic fibrosing alveolitis and lung cancer. Thorax 35: 496-499, 1980.

16. Stack BH, Grant IW, Irvine WJ and Moffat MA: Idiopathic diffuse interstitial lung disease. A review of 42 cases. Am Rev Respir Dis 92: 939-948, 1965.

17. Tomassetti S, Gurioli C, Ryu JH, Decker PA, Ravaglia C, Tantalocco P, Buccioli M, Piciucchi S, Sverzellati N, Dubini A, et al: The impact of lung cancer on survival of idiopathic pulmonary fibrosis. Chest 147: 157-164, 2015.

18. Aubry MC, Myers JL, Douglas WW, Tazelaar HD, Washington Stephens TL, Hartman TE, Deschamps C and Pankratz VS: Primary pulmonary carcinoma in patients with idiopathic pulmonary fibrosis. Mayo Clin Proc 77: 763-770, 2002.

19. Nagai A, Chiyotani A, Nakadate T and Konno K: Lung cancer in patients with idiopathic pulmonary fibrosis. Tohoku J Exp Med 167: 231-237, 1992.

20. Park J, Kim DS, Shim TS, Lim CM, Koh Y, Lee SD, Kim WS, Kim WD, Lee JS and Song KS: Lung cancer in patients with idiopathic pulmonary fibrosis. Eur Respir J 17: 1216-1219, 2001.

21. Kishi K, Homma S, Kurosaki A, Motoi N and Yoshimura K: High-resolution computed tomography findings of lung cancer associated with idiopathic pulmonary fibrosis. J Comput Assist Tomogr 30: 95-99, 2006.

22. Kim Y, Kwon Y, Oh I, Kim K, Kim S, Ryu J, Yum H, Yong S, Lee K, Lee C, et al: National survey of lung cancer in Korea, 2005. J Lung Cancer 6: 67-73, 2007.

23. Lee C, Kang KH, Koh Y, Chang J, Chung HS, Park SK, Yoo K and Song JS: Characteristics of lung cancer in Korea, 1997. Lung Cancer 30: 15-22, 2000.

24. Hironaka M and Fukayama M: Pulmonary fibrosis and lung carcinoma: A comparative study of metaplastic epithelia in honeycombed areas of usual interstitial pneumonia with or without lung carcinoma. Pathol Int 49: 1060-1066, 1999.

25. Takahashi T, Munakata M, Ohtsuka Y, Nisihara H, Nasuhara Y, Kamachi-Satoh A, Dosaka-Akita H, Homma Y and Kawakami Y: Expression and alteration of ras and p53 proteins in patients with lung carcinoma accompanied by idiopathic pulmonary fibrosis. Cancer 95: 624-633, 2002.

26. Kawasaki H, Ogura T, Yokose T, Nagai K, Nishiwaki Y and Esumi H: p53 gene alteration in atypical epithelial lesions and carcinoma in patients with idiopathic pulmonary fibrosis. Hum Pathol 32: 1043-1049, 2001.

27. Oshikawa K and Sugiyama Y: Serum anti-p53 autoantibodies from patients with idiopathic pulmonary fibrosis associated with lung cancer. Respir Med 94: 1085-1091, 2000.

28. Zhong G, Chen X, Fang X, Wang D, Xie M and Chen Q: Fra-1 is upregulated in lung cancer tissues and inhibits the apoptosis of lung cancer cells by the P53 signaling pathway. Oncol Rep 35: 447-453, 2016.

29. Liu ZH, Wang MH, Ren HJ, Qu W, Sun LM, Zhang QF, Qiu XS and Wang EH: Interleukin 7 signaling prevents apoptosis by regulating bcl-2 and bax via the p53 pathway in human non-small cell lung cancer cells. Int J Clin Exp Pathol 7: 870-881, 2014.

30. Li S, Li X, Zhao H, Gao M, Wang F and Li W: Overexpression of microRNA-125a-3p effectively inhibits the cell growth and invasion of lung cancer cells by regulating the mouse double minute 2 homolog/p53 signaling pathway. Mol Med Rep 12: 5482-5486, 2015.

31. Chuang CY, Liu HC, Wu LC, Chen CY, Chang JT and Hsu SL: Gallic acid induces apoptosis of lung fibroblasts via a reactive oxygen species-dependent ataxia telangiectasia mutated-p53 activation pathway. J Agric Food Chem 58: 2943-2951, 2010. 
32. Fu X, Ravindranath L, Tran N, Petrovics G and Srivastava S: Regulation of apoptosis by a prostate-specific and prostate cancer-associated noncoding gene, PCGEM1. DNA Cell Biol 25: 135-141, 2006.

33. Gupta RA, Shah N, Wang KC, Kim J, Horlings HM, Wong DJ, Tsai MC, Hung T, Argani P, Rinn JL, et al: Long non-coding RNA HOTAIR reprograms chromatin state to promote cancer metastasis. Nature 464: 1071-1076, 2010.

34. Cao G, Zhang J, Wang M, Song X, Liu W, Mao C and Lv C: Differential expression of long non-coding RNAs in bleomycin-induced lung fibrosis. Int J Mol Med 32: 355-364, 2013.

35. Ricciuti B, Mencaroni C, Paglialunga L, Paciullo F, Crinò L, Chiari R and Metro G: Long noncoding RNAs: New insights into non-small cell lung cancer biology, diagnosis and therapy. Med Oncol 33: 18, 2016.

36. Wang HM, Lu JH, Chen WY and Gu AQ: Upregulated IncRNA-UCA1 contributes to progression of lung cancer and is closely related to clinical diagnosis as a predictive biomarker in plasma. Int J Clin Exp Med 8: 11824-11830, 2015.

37. Khandelwal A, Bacolla A, Vasquez KM and Jain A: Long non-coding RNA: A new paradigm for lung cancer. Mol Carcinog 54: 1235-1251, 2015.

38. Lopez-Pajares V: Long non-coding RNA regulation of gene expression during differentiation. Pflugers Arch 468: 971-981, 2016.

39. Ebisuya M, Yamamoto T, Nakajima M and Nishida E: Ripples from neighbouring transcription. Nat Cell Biol 10: 1106-1113, 2008.

40. Huang C, Yang Y and Liu L: Interaction of long noncoding RNAs and microRNAs in the pathogenesis of idiopathic pulmonary fibrosis. Physiol Genomics 47: 463-469, 2015.

41. Mercer TR, Dinger ME, Sunkin SM, Mehler MF and Mattick JS: Specific expression of long noncoding RNAs in the mouse brain. Proc Natl Acad Sci USA 105: 716-721, 2008.

42. Rinn JL, Kertesz M, Wang JK, Squazzo SL, Xu X, Brugmann SA, Goodnough LH, Helms JA, Farnham PJ, Segal E and Chang Y: Functional demarcation of active and silent chromatin domains in human HOX loci by noncoding RNAs. Cell 129: 1311-1323, 2007.

43. Willingham AT, Orth AP, Batalov S, Peters EC, Wen BG, Aza-Blanc P, Hogenesch JB and Schultz PG: A strategy for probing the function of noncoding RNAs finds a repressor of NFAT. Science 309: 1570-1573, 2005.

44. Bayoglu B, Yuksel H, Cakmak HA, Dirican A and Cengiz M: Polymorphisms in the long non-coding RNA CDKN2B-AS1 may contribute to higher systolic blood pressure levels in hypertensive patients. Clin Biochem 49: 821-827, 2016.

45. Timofeeva MN, Hung RJ, Rafnar T, Christiani DC, Field JK, Bickeböller H, Risch A, McKay JD, Wang Y, Dai J, et al: Influence of common genetic variation on lung cancer risk: Meta-analysis of 14900 cases and 29485 controls. Hum Mol Genet 21: 4980-4995, 2012
46. Ørom UA, Derrien T, Beringer M, Gumireddy K, Gardini A, Bussotti G, Lai F, Zytnicki M, Notredame C, Huang Q, et al: Long noncoding RNAs with enhancer-like function in human cells. Cell 143: 46-58, 2010.

47. Mattick JS: Linc-ing long noncoding RNAs and enhancer function. Dev Cell 19: 485-486, 2010.

48. Cho RJ, Campbell MJ, Winzeler EA, Steinmetz L, Conway A, Wodicka L, Wolfsberg TG, Gabrielian AE, Landsman D, Lockhart DJ and Davis RW: A genome-wide transcriptional analysis of the mitotic cell cycle. Mol Cell 2: 65-73, 1998.

49. Kruglyak S and Tang H: Regulation of adjacent yeast genes. Trends Genet 16: 109-111, 2000.

50. Cohen BA, Mitra RD, Hughes JD and Church GM: A computational analysis of whole-genome expression data reveals chromosomal domains of gene expression. Nat Genet 26: 183-186, 2000.

51. Quelle DE, Zindy F, Ashmun RA and Sherr CJ: Alternative reading frames of the INK4a tumor suppressor gene encode two unrelated proteins capable of inducing cell cycle arrest. Cell 83: 993-1000, 1995.

52. Kamb A, Gruis NA, Weaver-Feldhaus J, Liu Q, Harshman K, Tavtigian SV, Stockert E, Day RS III, Johnson BE and Skolnick MH: A cell cycle regulator potentially involved in genesis of many tumor types. Science 264: 436-440, 1994.

53. Huang SK, Scruggs AM, McEachin RC, White ES and Peters-Golden M: Lung fibroblasts from patients with idiopathic pulmonary fibrosis exhibit genome-wide differences in DNA methylation compared to fibroblasts from nonfibrotic lung. PLoS One 9: e107055, 2014

54. Li J, Bi L, Sun Y, Lu Z, Lin Y, Bai O and Shao H: Text mining and network analysis of molecular interaction in non-small cell lung cancer by using natural language processing. Mol Biol Rep 41: 8071-8079, 2014.

55. Cisneros J, Hagood J, Checa M, Ortiz-Quintero B, Negreros M, Herrera I, Ramos C, Pardo A and Selman M: Hypermethylation-mediated silencing of p14(ARF) in fibroblasts from idiopathic pulmonary fibrosis. Am J Physiol Lung Cell Mol Physiol 303: L295-L303, 2012.

This work is licensed under a Creative Commons Attribution-NonCommercial-NoDerivatives 4.0 International (CC BY-NC-ND 4.0) License. 